\title{
Carbon stable isotope discrimination: a possible growth index for the kelp Undaria pinnatifida
}

\author{
Matheus Carvalho de Carvalho*, Ken-Ichi Hayashizaki, Hisao Ogawa
}

Kitasato University, School of Marine Biosciences, 160-4 Utou, Okkirai, Sanriku-cho, Ofunato, Iwate 022-0101, Japan

\begin{abstract}
Undaria pinnatifida sporophytes were grown in a marine bay under differing culture conditions in order to obtain individuals with different growth rates. Carbon stable isotope compositions of seawater and cultured algae were measured to calculate carbon stable isotope discrimination due to carbon assimilation $(\Delta)$ by the thalli. High and significant correlations were found between growth rates (absolute in length, absolute in weight, or relative in weight) and $\Delta$, which suggests that growth rate was the most important factor determining $\Delta$. The correlation between $\Delta$ and relative growth rate in weight was especially good, following the formula: $\Delta=28.6-1.4 \mathrm{RGR}(\mathrm{r}=-0.97)$, in which RGR is the relative growth rate in weight $\left(\% \mathrm{~d}^{-1}\right)$. This very good correlation, if confirmed for other instances, would allow $\Delta$ to be used as a growth index for the species. Results also suggested that $\mathrm{HCO}_{3}^{-}$uptake may be the main mechanism of inorganic carbon assimilation for the studied species.
\end{abstract}

KEY WORDS: $\delta^{13} \mathrm{C} \cdot$ Seaweed $\cdot$ Primary production $\cdot$ Field experiment $\cdot$ Growth analysis

\section{INTRODUCTION}

Carbon has 2 stable isotopes with atomic masses of 12 and 13. The natural abundance of these isotopes is usually expressed as the $\delta^{13} \mathrm{C}$ of the substance, with higher $\delta^{13} \mathrm{C}$ values meaning a greater proportional amount of the heavier ${ }^{13} \mathrm{C}$. Terrestrial $\mathrm{C}_{3}$ plants have $\delta^{13} \mathrm{C}$ around $-28 \%$, while $\mathrm{C}_{4}$ plants have a value around $-13 \%$ (Peterson \& Fry 1987). Marine phytoplankton has a $\delta^{13} \mathrm{C}$ of $-22 \%$, on average (France 1995). These differences in the $\delta^{13} \mathrm{C}$ of primary producers have allowed the use of $\delta^{13} \mathrm{C}$ to elucidate the relative importance of each group of primary producers in different ecosystems (Peterson \& Fry 1987). However, the $\delta^{13} \mathrm{C}$ of seaweeds varies widely, from less than $-35 \%$ o to more than $-3 \%$ (Raven et al. 2002), a range that encompasses practically all the known values for all primary producers (Peterson \& Fry 1987, France 1995). Hence, in ecosystems where seaweeds are important primary producers, the application of $\delta^{13} \mathrm{C}$ to determine the sources of carbon is difficult. On the other hand, the wide variation of $\delta^{13} \mathrm{C}$ among sea- weeds has been used to better understand their ecophysiology (Maberly et al. 1992).

The $\delta^{13} \mathrm{C}$ value of a seaweed depends on 2 quantities: the $\delta^{13} \mathrm{C}$ of the carbon source and the isotope discrimination during carbon assimilation. Discrimination is indicated by $\Delta$ (O'Leary 1981) such that:

$$
\Delta=\left(\delta^{13} \mathrm{C}_{\mathrm{s}}-\delta^{13} \mathrm{C}_{\mathrm{p}}\right) /\left(1+\delta^{13} \mathrm{C}_{\mathrm{s}} / 1000\right)
$$

where the subscripts $\mathrm{s}$ and p mean source and plant, respectively. Since the denominator in the formula is nearly equal to $1, \Delta$ can be approximated by the difference between the $\delta^{13} \mathrm{C}_{\mathrm{s}}$ and $\delta^{13} \mathrm{C}_{\mathrm{p}}$. The carbon source for seaweeds is the inorganic carbon in seawater, the $\delta^{13} \mathrm{C}$ of which is expected to be reasonably uniform in surface marine waters (Kroopnick 1985). However, in some coastal environments, rivers can change the dissolved inorganic carbon (DIC) $\delta^{13} \mathrm{C}$ values (Chanton \& Lewis 1999) and, in the tidal zone, biological activity in tidal pools and air exposure both influence the composition of the carbon source for some seaweeds (Surif \& Raven 1990, Maberly et al. 1992). Even in relatively stable environments, like the sublittoral zone, in places 
without large river influence, the $\delta^{13} \mathrm{C}$ of the source will be different according to the chemical species of inorganic carbon absorbed, $\mathrm{CO}_{2}$ or $\mathrm{HCO}_{3}^{-}$(Mook et al. 1974). $\Delta$ is also subject to considerable variation. Evidence exists that the thickness of the boundary layer around the thallus (Raven et al. 1982), the leakage during carbon uptake (Sharkey \& Berry 1985, Maberly et al. 1992), and photosynthetic intensity (Wiencke \& Fischer 1990, Kübler \& Raven 1994, 1995) all influence $\Delta$. Although the listed factors affecting seaweed $\delta^{13} \mathrm{C}$ are many, it is possible that one of them be more important than the others in specific environmental conditions.

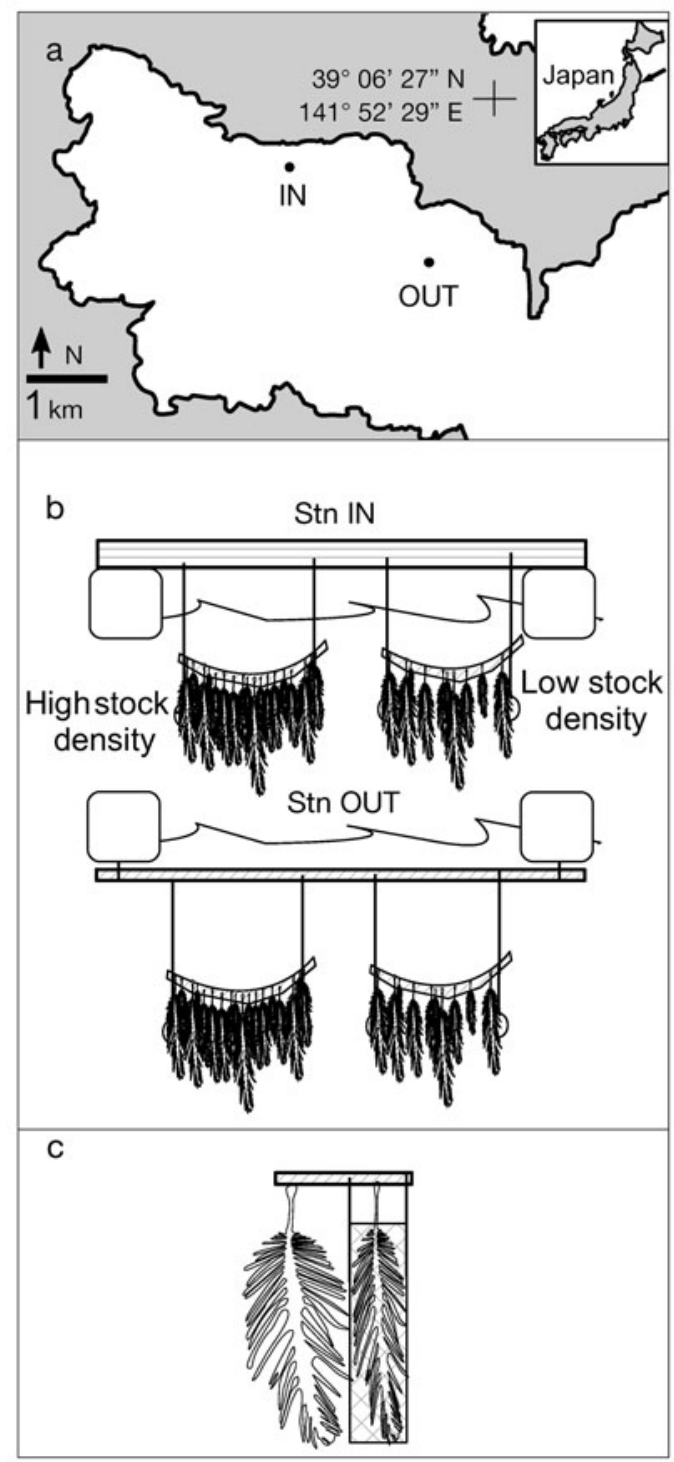

Fig. 1. Details of the experiments. (a) Locations of experiments (Stations IN and OUT); (b) scheme of the culture ropes, showing the raft at Stn IN and the support rope at Stn OUT; (c) thallus covered with mesh (right) beside an uncovered thallus (left)
For example, it has been found on several occasions that light intensity apparently was the most important environmental factor to determine the $\delta^{13} \mathrm{C}$ of seaweeds and seagrasses (Wefer \& Killingley 1986, Cooper \& DeNiro 1989, Grice et al. 1996), which has been interpreted as the regulation of $\Delta$ by carbon assimilation intensity. In agreement with these results, we found that the $\delta^{13} \mathrm{C}$ of cultured Undaria pinnatifida in Okkirai Bay, northeastern Japan, seemed to be influenced by its growth rate (Carvalho et al. 2007).

Undaria pinnatifida is a kelp heavily cultured in Japan, where it is an important food resource (Ogawa 2004). The species has also become notorious as an invader in several parts of the world, due to its high potential to outcompete others (Hay \& Luckens 1987, Casas et al. 2004). Cultured U. pinnatifida grows very fast, often reaching $>2.5 \mathrm{~m}$ in length in $<4 \mathrm{mo}$ of culture. The growth pattern is complex, involving a change from a leaf-like thallus to a thallus consisting of a central midrib and pinnate blade, followed by the development of the sporophyll (reproductive organ). Despite this, total length is strongly correlated with total weight (Yoshikawa et al. 2001), which allows the estimation of growth rates and primary production for the species based on thallus length.

We aimed here to investigate the possible correlation between growth and $\Delta$ that was suggested in our previous research (Carvalho et al. 2007). In order to do so, we carried out 2 experiments in 2 consecutive years, in which we measured sporophyte growth and $\delta^{13} \mathrm{C}$, as well as the $\delta^{13} \mathrm{C}$ of seawater. As shown, growth rate seems to be the main factor affecting $\Delta$ in this species in the natural environment. Moreover, the correlation between growth rate and $\Delta$ was sufficient to suggest that $\Delta$ might be an applicable growth index for the species, although confirmatory investigations under other environmental conditions are necessary. Finally, the results were also useful in indicating the chemical form of inorganic carbon being taken up by the species.

\section{MATERIALS AND METHODS}

Two experiments were carried out: one from November 2006 to February 2007 and another from November 2007 to February 2008. These times were chosen to take advantage of the usual culture season of Undaria pinnatifida, from late November to mid-April (Ogawa 2004).

2007 experiment. Four experimental culture ropes of approximately $1 \mathrm{~m}$ in length each were set in Okkirai Bay, northeastern Japan, at 2 stations (Fig. 1a). These stations were chosen based on the empirical knowledge of local fishermen that growth of Undaria pinnatifida at Stn IN is generally poorer than at Stn OUT. At 
Stn OUT, 2 experimental culture ropes were connected to an existing culture facility, and, at Stn IN, 2 more were placed under a raft (Fig. 1b). At both stations, the thalli were at approximately the same depth, nearly $1 \mathrm{~m}$ from the water surface. On each experimental rope, 1 or 2 strings with $>2$ small thalli $\mathrm{cm}^{-1}$, which had been purchased from the local fishermen cooperative, were tied so that 4 culture conditions existed: low and high stock density at Stn OUT and at Stn IN. To keep thallus density low in the appropriate treatment groups, thalli with poor growth were periodically cut from the ropes. The culture was started on November 30,2006 . In another experiment, which was initiated on January 16, 2007, 3 thalli from the low stock density rope at Stn OUT and 3 other thalli from the high stock density rope at the same station were wrapped with a $1 \mathrm{~cm}$ square mesh in order to disturb their growth (Fig. 1c). The thalli were kept submerged continuously, except during sampling occasions. Experiments were completed by February 5, 2007, that is, with the thalli still immature.

The experimental culture ropes were taken to the laboratory on 3 occasions (December 29, 2006, and January 16 and February 5, 2007) in order to measure thallus growth and to collect samples for carbon stable isotope measurements. The thalli were kept in a tank with continuous seawater flow until the following day, when they were returned to the sea. The growth rate was measured using the punch-hole method (Brinkhuis 1985): the midrib was perforated at a known distance from the base of the thallus by a hole with a diameter of $0.4 \mathrm{~cm}$; several days later, the distance from the hole to the base was measured. These measurements were used to calculate absolute growth rate in length $\left(A G R_{L}\right)$ :

$$
\mathrm{AGR}_{\mathrm{L}}=\left(L_{2}-L_{1}\right) /\left(t_{2}-t_{1}\right)
$$

where AGR is the growth rate in centimeters per day, $L$ is the distance in centimeters from the base to the punched hole at the sampling times, and $t$ is the time in days. Growth measurements began on December 29, 2006 , in order to let the thalli grow and to enable us to punch the hole. The $t_{1}$ in Eq. (2) was December 29, 2006, when $t_{2}$ was January 16, 2007, or $t_{1}$ was January 16, 2007, when $t_{2}$ was February 5, 2007.

$\mathrm{AGR}_{\mathrm{L}}$ can be converted to $\mathrm{AGR}_{\mathrm{W}}$ (the absolute growth rate in weight) by also considering the total length (TL) at the beginning of the measurement and by applying an equation to convert total length to total weight (Yoshikawa et al. 2001). In the 2007 experiment, we measured the total length of some individuals, but did not measure weight to obtain the relationship between total length and total weight. However, in the 2008 experiment, we did such measurements (details below); thus, we were able to apply that equa- tion to the 2007 data and estimate $A G R_{W}$, which is defined by the formula:

$$
\mathrm{AGR}_{\mathrm{W}}=\left(\mathrm{TW}_{2}-\mathrm{TW}_{1}\right) /\left(t_{2}-t_{1}\right)
$$

where TW is total weight. Although $\mathrm{AGR}_{\mathrm{W}}$ is less biased than $\mathrm{AGR}_{\mathrm{L}}$, an even more preferable measure is the relative growth rate (RGR), because it removes biases related to plant size (Evans 1972, Hunt 1982). It is defined by:

$$
\mathrm{RGR}=\left[\ln \left(\mathrm{TW}_{2}\right)-\ln \left(\mathrm{TW}_{1}\right)\right] /\left(t_{2}-t_{1}\right)
$$

At $t_{2}, 2$ holes were made, one near the previously punched hole and another near the base of the thallus. The punched out samples at $t_{2}$ were rinsed with distilled water to remove seawater, dried at $60^{\circ} \mathrm{C}$ until constant weight and kept in a desiccator until carbon stable isotope measurements. These samples were small enough so that powdering was not necessary. The samples were folded into tin crucibles and burned in an elemental analyzer (Flash EA, Thermo Fisher). The combustion gases flowed through a flow controller (ConFlo, Thermo Fisher) to a mass spectrometer

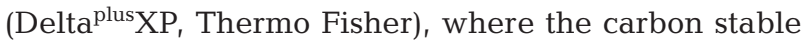
isotope composition of the $\mathrm{CO}_{2}$ originating from the combustion of the sample was measured. L-alanin, a working standard, was used as a reference for the measured samples. Repeated measurements of the standard showed a standard deviation of $0.2 \%$ or less.

Water at Stns OUT and IN was collected approximately every $10 \mathrm{~d}$ to monitor environmental conditions. Salinity and temperature were measured in situ using a conductivity meter (WTW, Model LF 340). Bottles designed for the measurement of dissolved oxygen were used to maintain samples for $\mathrm{pH}$ and alkalinity measurements, in order to avoid prolonged contact between the water sample and air. In the laboratory, $\mathrm{pH}$ and alkalinity were measured using a $\mathrm{pH}$ meter (IQ Scientific Instruments, Model IQ240). Alkalinity was calculated by Gran titration with $\mathrm{HCl}(0.1 \mathrm{~N})$ following the procedures described in Stumm \& Morgan (1981). Alkalinity and $\mathrm{pH}$ were then used to calculate total dissolved inorganic carbon (DIC) concentration, as well as the concentrations of $\mathrm{CO}_{2}, \mathrm{HCO}_{3}{ }^{-}$and $\mathrm{CO}_{3}{ }^{2-}$, using the equilibrium constants for seawater listed in Stumm \& Morgan (1981) and applying the correction for boron content. Aliquots of these samples destined for stable isotope analysis of DIC were transferred to Falcon tubes $(10 \mathrm{ml})$, taking care to avoid trapping air, and kept in a refrigerator (approximately $4^{\circ} \mathrm{C}$ ) for at most 2 mo until measurements. No poisons were added. The measurement of DIC $\delta^{13} \mathrm{C}$ was done using a GasBench (Thermo Fisher) connected to the mass spectrometer. Approximately $30 \mu \mathrm{l}$ of phosphoric acid (reagent grade) was added to borosilicate vials (10 $\mathrm{ml}$ of capacity), which were closed using a screw cap with a rub- 
ber membrane that allowed perforation by syringe needles. The closed vials were flushed with helium gas for approximately $8 \mathrm{~min}$ in order to remove the air, and then about $0.7 \mathrm{ml}$ of the seawater sample was added to each vial using a syringe, taking care to avoid contamination by air. The vials were left in a sample tray at $32^{\circ} \mathrm{C}$ for $18 \mathrm{~h}$, and then the stable isotope composition of the $\mathrm{CO}_{2}$ in the vial was measured. Measurements were carried out in duplicate. Based on these measurements, the $\delta^{13} \mathrm{C}$ values of $\mathrm{CO}_{2}$ and $\mathrm{HCO}_{3}{ }^{-}$were calculated using the relationships shown in Mook et al. (1974), following the procedures explained by Maberly et al. (1992) or by Zeebe \& Wolf-Gladrow (2001).

In order to obtain $\Delta$ from Eq. (1), it is necessary to know $\delta^{13} \mathrm{C}_{\mathrm{p}}$ and $\delta^{13} \mathrm{C}_{\mathrm{s}} \cdot \delta^{13} \mathrm{C}_{\mathrm{p}}$ was approximated as the average of the 2 values measured from the punched out samples at $t_{2} . \delta^{13} \mathrm{C}_{\mathrm{s}}$ was assumed to be the average DIC $\delta^{13} \mathrm{C}$ during the growth period. This value should be very similar to average $\mathrm{HCO}_{3}{ }^{-} \delta^{13} \mathrm{C}$, and $\mathrm{HCO}_{3}{ }^{-}$may be the main source of carbon for Laminariales, although this is not clear (Surif \& Raven 1989). The validity of this assumption is evaluated in the 'Discussion' section.

2008 experiment. This experiment was very similar to that in 2007, and only the main differences in the methodology will be described here. The experiment was started on November 23, 2007, and continued until January 29, 2008. Cultures were carried out at Stns OUT and IN, but only low stock density was used. Growth was quantified based on total length; this method was chosen as thalli were very small and it was not possible to punch holes. However, for the culture period in this experiment, which involved only young thalli, erosion of the tip of the thallus was small (Yoshikawa et al. 2001), so that measurements based on total length and those based on the punch hole should yield very similar results. $\mathrm{AGR}_{\mathrm{W}}$ and RGR were calculated by conversion of total length to total weight using a regression equation. This equation was obtained by measuring and weighing several cultured individuals (other than those used for the isotopic experiment) of different sizes. Total length was measured at approximately $10 \mathrm{~d}$ intervals, at which time seawater was also collected for analysis. A tag fixed beside each individual identified it.

At the end of the incubation, the thalli were removed from the culture ropes, brought to the laboratory, and each individual was cut in 3 or 4 transversal sections. These sections were dried at $60^{\circ} \mathrm{C}$ until constant weight and kept in a desiccator until $\delta^{13} \mathrm{C}$ measurement. On this occasion, the different sections were pooled together for each individual in 1 mixed sample (nearly $2 \mathrm{mg}$ in weight), and this sample was analyzed as representing the entire thallus $\left(\delta^{13} C_{p}\right)$. Each measurement was carried out in duplicate. Analysis of sea- water was done as in 2007, except that, to quantify [DIC], we were only able to measure $\mathrm{pH}$ and alkalinity at the beginning of the experiment. The calculations needed to determine $\delta^{13} \mathrm{C}$ of $\mathrm{HCO}_{3}{ }^{-}$and $\mathrm{CO}_{2}$ were done assuming that [DIC] remained constant during the experimental period.

Statistics. In the present study, the ultimate aim was to try to find a connection between the growth rate and $\Delta$. The strategy was to try to force thalli to grow at different rates; to this end, several experimental factors were employed that allowed formal statistical testing of the factors that affected growth rates and $\Delta$. However, it was not the objective of the present study to carry out such comparisons, and the number of replications was not sufficient for robust or even correct testing. Therefore, statistical tests were not conducted for these results, as is recommended in such cases (Hurlbert 1984).

Two-way ANOVA was conducted to compare the environmental conditions between stations and years, in order to test for similarity of experimental conditions among the experimental groups.

The corrected Akaike information criterion (AICc) was employed to choose the best model for the regression fit between growth rate and $\Delta$ in each case. This was done because there was no reason a priori to choose any particular fit. Two models were tested: linear and power. The model whose fit showed lowest AICc was chosen (Maindonald \& Braun 2007). The significance of the chosen regression fits was also checked through a Student's $t$-test.

All tests were carried out using the software KyPlot (KyensLab), and the significance level $(\alpha)$ was set at $5 \%$.

\section{RESULTS}

\section{Water quality}

In general, environmental conditions in both years and at both stations looked quite similar (Fig. 2). Twoway ANOVA tests (factors year and station) were conducted for each variable when possible. Differences were not significant regarding station, but salinity and $\delta^{13} \mathrm{C}$ differed between years: salinity averaged 33.8 psu in 2007 and 34.1 psu in 2008; DIC $\delta^{13} \mathrm{C}$ averaged $-0.1 \%$ in 2007 and $0.3 \%$ o in 2008 , and the calculated $\delta^{13} \mathrm{C}$ of $\mathrm{HCO}_{3}^{-}$and $\mathrm{CO}_{2}$ also differed between years. The interaction term of the ANOVA was not significant for any parameter. Despite the significant differences between 2007 and 2008 in salinity and in $\delta^{13} \mathrm{C}$, the magnitude of these differences was small, and, therefore, the differences probably did not influence thallus growth or $\delta^{13} \mathrm{C}$. 
2007
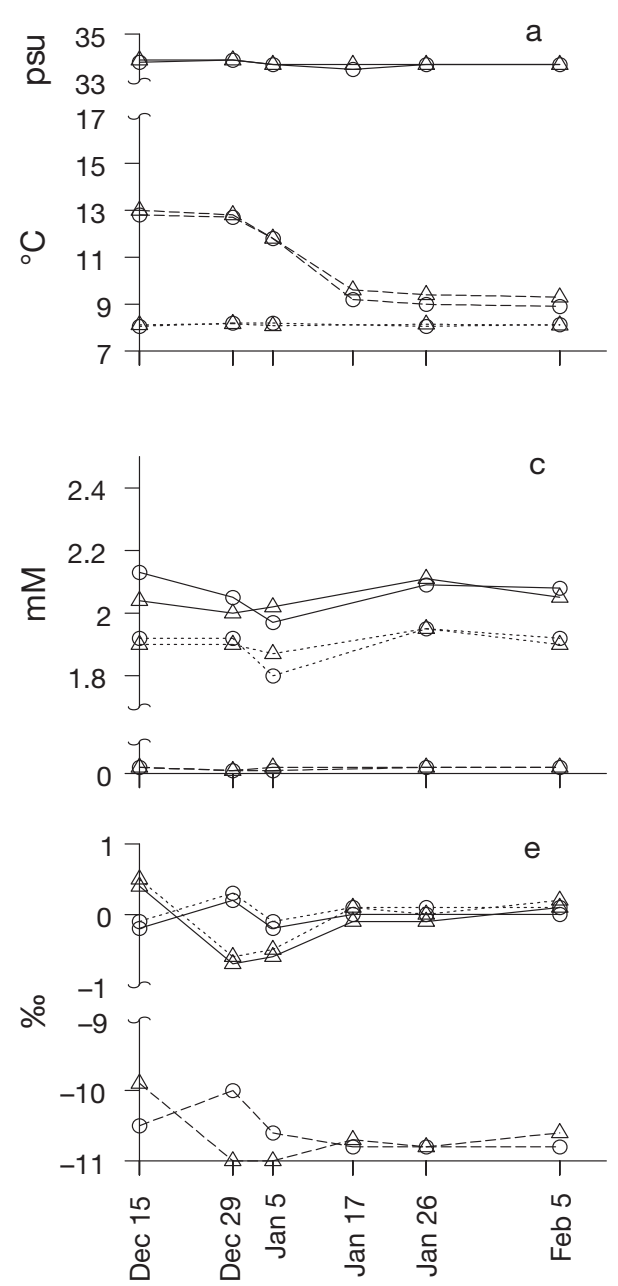

2008

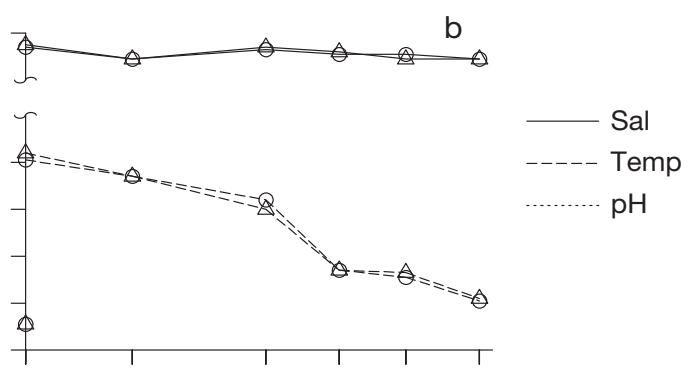

d
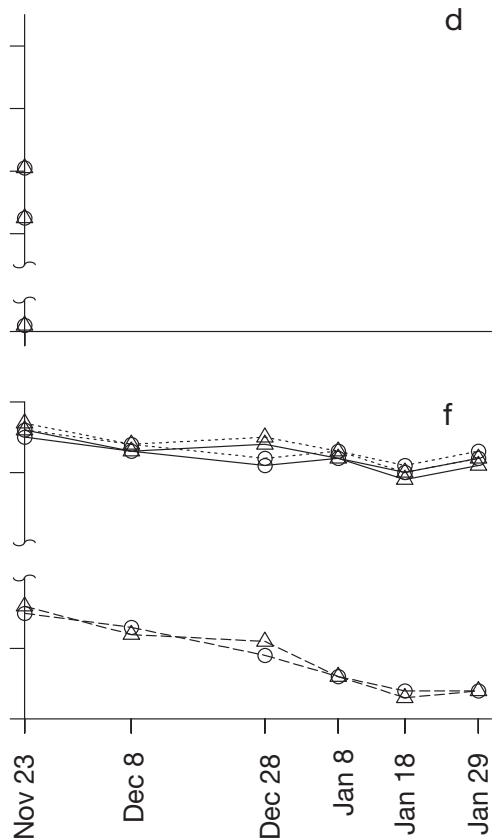

Fig. 2. Water quality measurements in 2007 (a, c, e) and 2008 (b, d, f). (a, b) Salinity, temperature and pH; (c, d) concentrations of dissolved inorganic carbon (DIC), $\mathrm{CO}_{2}$ and $\mathrm{HCO}_{3}{ }^{-}$and $(\mathrm{e}, \mathrm{f}) \mathrm{DIC} \delta^{13} \mathrm{C}_{1} \mathrm{CO}_{2} \delta^{13} \mathrm{C}$ and $\mathrm{HCO}_{3}{ }^{-} \delta^{13} \mathrm{C}$. Circles: measurements for Stn IN; triangles: measurement for Stn OUT

Temperature showed a temporal trend of decreasing values (Fig. 2a, b). The sharpest decrease in both years occurred between December and January (from 13 to $10^{\circ} \mathrm{C}$ ). Salinity and $\mathrm{pH}$ were very stable over time in both 2007 and 2008 (Fig. 2a,b). [DIC] oscillated between 2.00 and $2.10 \mathrm{mM}$ in 2007 (Fig. 2c). Trends in $\left[\mathrm{CO}_{2}\right]$ and $\left[\mathrm{HCO}_{3}^{-}\right]$more or less mirrored that of [DIC]. DIC $\delta^{13} \mathrm{C}$ did not show any clear trend in 2007, and values tended to be different between stations at the beginning of the experiment, with relatively high oscillation (approximately -0.5 to $0.5 \%$ ), followed by constant values for both stations around $0.0 \%$ (Fig. 2e). In 2008, DIC $\delta^{13} \mathrm{C}$ slightly decreased with time, from $0.5 \%$ at both stations in November to approximately $0.0 \%$ at both stations in January (Fig. 2f). Trends in $\mathrm{CO}_{2}$ and $\mathrm{HCO}_{3}{ }^{-} \delta^{13} \mathrm{C}$ more or less mirrored that of DIC $\delta^{13} \mathrm{C}$.

The lack of pH and [DIC] data in 2008 does not compromise the analysis: even though salinity differed sta- tistically between 2007 and 2008, the averages are similar enough to assume that [DIC] was not very different between the 2 yr. Accordingly, the only [DIC] measured in 2008 showed a value similar to those measured in 2007. Moreover, if variation of [DIC] in the range of the values found in 2007 is assumed for values in 2008, only negligible influence is calculated for the $\delta^{13} \mathrm{C}$ of $\mathrm{HCO}_{3}{ }^{-}$and $\mathrm{CO}_{2}$ (results not shown), which are the values that matter for the analysis of isotopic discrimination.

\section{Thallus growth}

Average values for thallus development and growth rates are shown in Fig. 3. Weight values, as well as $\mathrm{AGR}_{\mathrm{W}}$ and RGR, were calculated based on the relationship between total length and weight as shown in Fig. 4. 
Trends in data from 2007 (left side of Fig. 3) were not as clear as those from 2008 (right side) due to the many experimental factors employed, but a careful examination reveals some trends in the data. Except for RGR
(Fig. 3i), all parameters were higher for thalli from Stn OUT. Average TL ranged from 30 to $80 \mathrm{~cm}$ at Stn OUT and from 30 to $60 \mathrm{~cm}$ at Stn IN, with considerable overlap among the error bars from the different
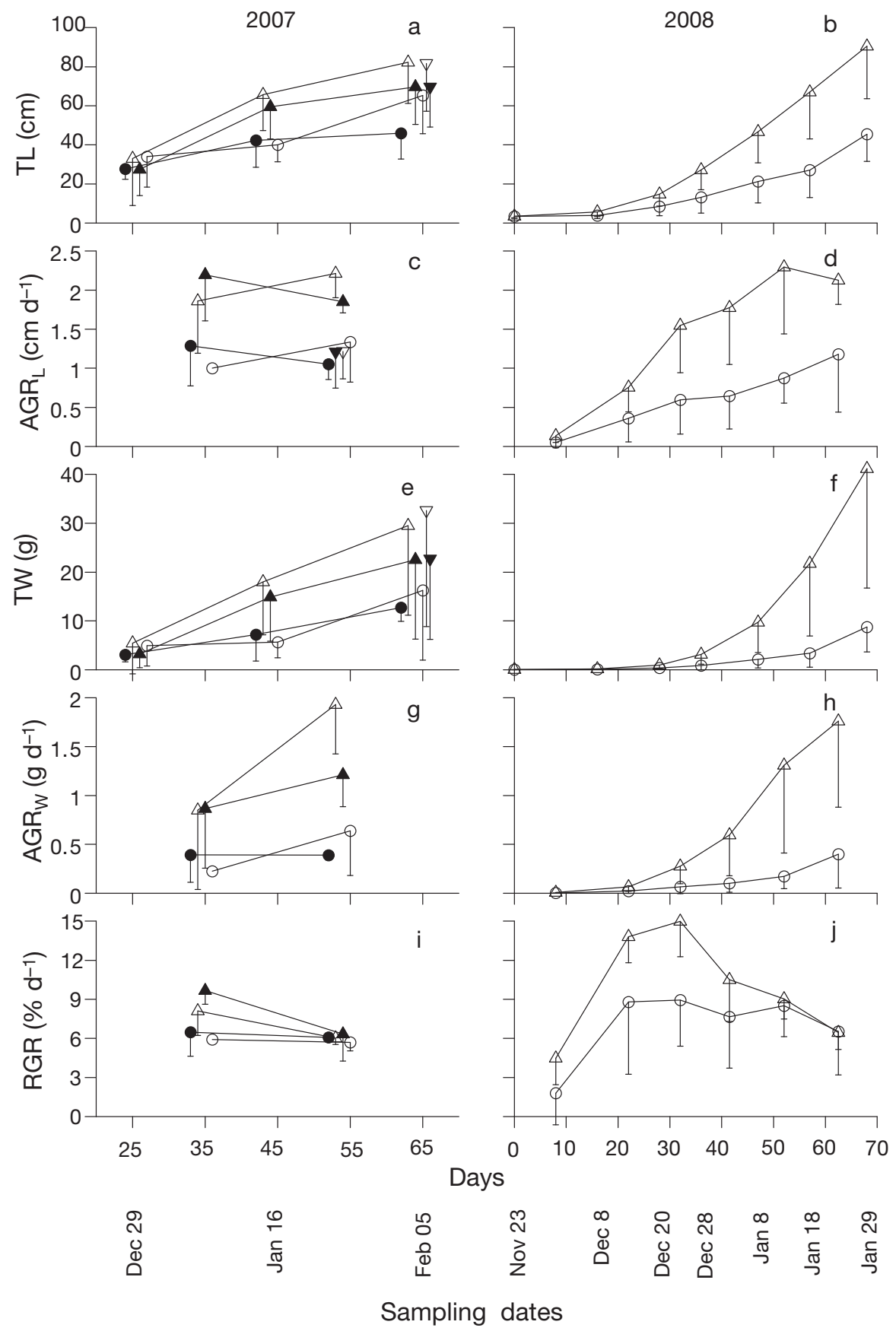

Fig. 3. Undaria pinnatifida. Averages (data points) and standard deviations (error bars) of parameters of thallus size and of growth

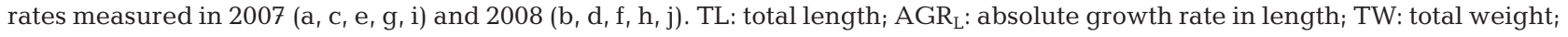
$\mathrm{AGR}_{\mathrm{W}}$ : absolute growth rate in weight; RGR: relative growth rate. Circles: measurements for Stn IN; triangles: measurements for Stn OUT; inverted triangles: thalli covered by mesh; open symbols: low stock density; closed symbols: high stock density. Data for a single date but from different treatments in 2007 are slightly offset for clarity. Note that growth rates are centered between sampling dates. Days on the $x$-axis indicate the number of days since initiation of the culture experiment 


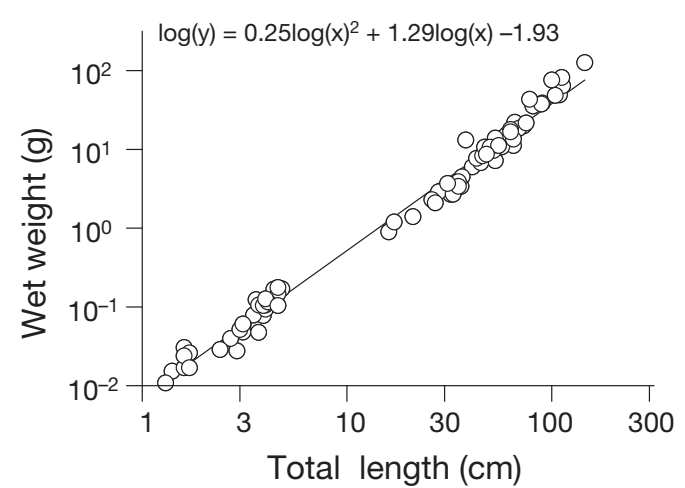

Fig. 4. Undaria pinnatifida. Empirical regression between total length and wet weight

treatments. $\mathrm{AGR}_{\mathrm{L}}$ averaged $2 \mathrm{~cm} \mathrm{~d}^{-1}$ at Stn OUT and around $1 \mathrm{~cm} \mathrm{~d}^{-1}$ at Stn IN and in the meshed thalli; average TW ranged from 5 to $30 \mathrm{~g}$ at Stn OUT and from 5 to $20 \mathrm{~g}$ at Stn IN, with considerable overlap among the treatments, similar to the TL values. $\mathrm{AGR}_{\mathrm{W}}$ averaged from 1 to $2 \mathrm{~g} \mathrm{~d}^{-1}$ at Stn OUT and $<0.5 \mathrm{~g} \mathrm{~d}^{-1}$ at Stn IN, and, similar to the values for $A_{G} R_{L}$, trends were clearer than those for size measurements (TL or TW). Average RGR was initially higher (around 9\% $\mathrm{d}^{-1}$ ) at Stn OUT, but later was around $6 \% \mathrm{~d}^{-1}$ at Stns OUT and IN. Stock density did not seem to affect average growth much, nor did the mesh.

In 2008, the difference between thalli from Stns IN and OUT was again observed (Fig. 3, right side). Initially, no difference was observed in most growth variables from different stations. However, as time passed thalli from Stn OUT showed much higher values of growth than those thalli from Stn IN. Average TL reached $90 \mathrm{~cm}$ at $S t n$ OUT, but only reached $40 \mathrm{~cm}$ at Station IN (Fig. 3b). $A_{\text {GR }}$ peaked at $>2 \mathrm{~cm} \mathrm{~d}^{-1}$ at Stn OUT, but barely reached $1 \mathrm{~cm} \mathrm{~d}^{-1}$ at Stn IN (Fig. 3d). Maximum average TW was $>40 \mathrm{~g}$ at Stn OUT (with considerable variation), but $<10 \mathrm{~g}$ at Stn IN (Fig. 3f). Average $\mathrm{AGR}_{\mathrm{W}}$ peaked at $1.8 \mathrm{~g} \mathrm{~d}^{-1}$ at $\mathrm{Stn}$ OUT, but did not reach $0.4 \mathrm{~g} \mathrm{~d}^{-1}$ at Stn IN (Fig. 3h). RGR reached $15 \% \mathrm{~d}^{-1}$ at Stn OUT, but did not reach $>9 \% \mathrm{~d}^{-1}$ at Stn IN, although values for the 2 stations became very similar from Day 50 of the experiment on (Fig. 3j).

\section{Thallus $\delta^{13} \mathrm{C}$ and $\Delta$}

$\delta^{13} \mathrm{C}$ varied among the groups in a way similar to the variation in growth rate, with higher values for Stn OUT than for Stn IN in both years, and no clear difference caused by stock density (Table 1). Values for thalli covered by mesh tended to be lower than those
Table 1. Undaria pinnatifida. Mean \pm SD (number of samples in parentheses) of $\delta^{13} \mathrm{C}(\%)$ in the cultured kelp

\begin{tabular}{|cccc|}
\hline Year & Station & Stock density & $\delta^{13} \mathrm{C}$ \\
\hline 2007 & OUT & Low & $-13.5 \pm 1.1(11)$ \\
& & Low + Mesh & $-15.6 \pm 1.4(6)$ \\
& & High & $-14.3 \pm 0.9(8)$ \\
& \multirow{2}{*}{ IN } & High + Mesh & $-15.6 \pm 2.3(6)$ \\
& & Low & $-15.9 \pm 1.3(6)$ \\
2008 & OUT & High & $-15.7 \pm 1.1(12)$ \\
& IN & Low & $-15.8 \pm 0.7(7)$ \\
& & & $-18.9 \pm 0.3(3)$ \\
\hline
\end{tabular}

for uncovered thalli (Table 1 ). $\delta^{13} \mathrm{C}$ was lower in thalli cultured in 2008 than in those cultured in 2007 (Table 1).

$\Delta$ results are shown in Fig. 5, together with individual growth rates. 2007 data consisted of the growth rates shown in Fig. 3 (averages and standard deviations). 2008 data consisted of growth rates calculated by considering $t_{1}$ Day 0 of incubation and $t_{2}$ the last day (68) of incubation. In all cases, high and significant correlations were found between $\Delta$ and the growth rates, except for RGR in 2007 (Fig. 5). The power function gave the best fit (lowest $\mathrm{AIC}_{\mathrm{c}}$ ) among those tested (linear and power functions) for $\mathrm{AGR}_{\mathrm{L}}$ and $\mathrm{AGR}_{\mathrm{W}}$, and the linear function provided the best fit for RGR. The best correlation was that found between $\Delta$ and RGR in 2008 (Fig. 5f).

It was strange that both the best and worst correlations shown in Fig. 5 were those between $\Delta$ and RGR. We supposed that this was due to the differences between the data used in 2007 and 2008, as explained above. The reason behind these differences may be that RGR of Undaria pinnatifida varied differently from $A G R_{W}$ and $A G R_{L}$, as seen in Fig. $3 d, h$ and $j$ : while $A G R_{W}$ and $A G R_{L}$ almost continually increased with time, RGR increased, was stable, or decreased substantially. We thus recalculated the growth rates for 2008 by retaining $t_{2}$ as the last day of measurement, but changing $t_{1}$ from Day 0 to Day 16, 28, 36, 47 or 57. Subsequently, we obtained the correlation coefficients between these new growth rates and $\Delta$ by plotting in the same way as shown in Fig. 5. Results of these procedures are shown in Table 2 . While changing $t_{1}$ barely changed the correlation between $\Delta$ and $\mathrm{AGR}_{\mathrm{W}}$ or $\mathrm{AGR}_{\mathrm{L}}$, it heavily affected the correlation with RGR. For $t_{1}=16$, the correlation was still significant, but from Day 28 on the correlation disappeared. This suggests that the lack of correlation observed for RGR and $\Delta$ in the 2007 data was probably due to the fact that RGR in that year did not cover a sufficient period of time to be related to $\Delta$. 

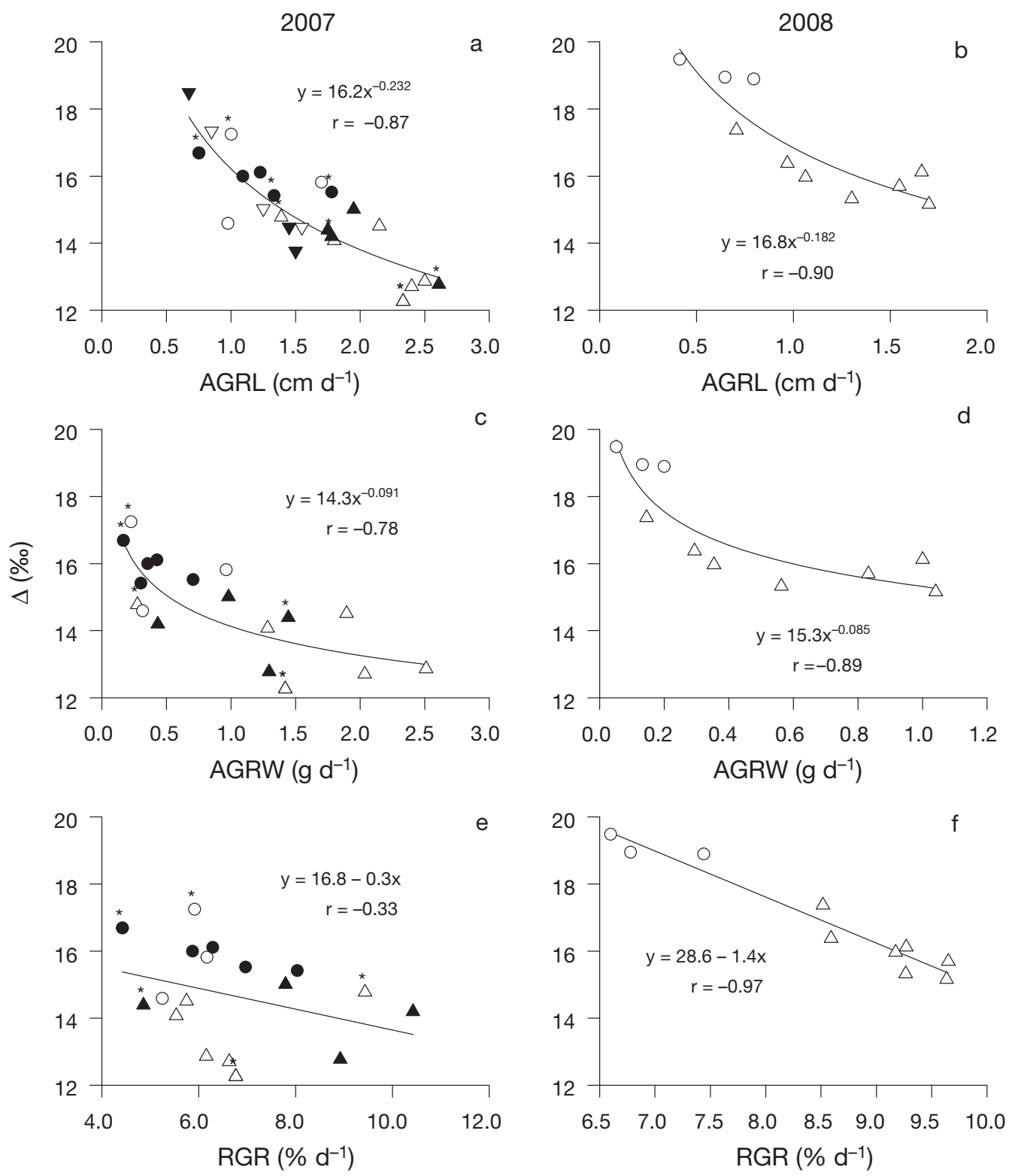

Fig. 5. Undaria pinnatifida. $\Delta$ plotted against the growth rates $A_{G R}(a, b), A_{G} R_{W}(c, d)$ and $R G R(e, f)$ for each thallus measured in 2007 (a, c, e) and 2008 (b, d, f). Symbols and abbreviations are as in Fig. 3. For the 2007 experiment, an asterisk indicates data obtained on January 16; other data were obtained on February 5. Growth rates in the 2008 experiment were calculated using data from Days 0 and 68

\section{DISCUSSION}

\section{Influence of environmental factors}

The difference between Stns OUT and IN concerning the growth of the cultured thalli was clear in both years (Fig. 3). The same can be said for thallus $\delta^{13} \mathrm{C}$ and $\Delta$ (Table 1, Fig. 5). However, measured environmental factors were quite similar between the 2 stations (Fig. 2). This demonstrates that none of the measured environmental factors can be isolated as the cause of the differences observed between the thalli from the 2 different locations. We assume that the most probable cause for the difference in thallus growth between Stns IN and OUT was that thalli at Stn IN were kept under a raft, while at Stn OUT they were cultured using the common culture ropes for Undaria pinnatifida. These latter structures are simply thick ropes to which thinner ones are attached; the thin ropes are then used to attach the thalli (Ogawa 2004). In this way, the thalli 
Table 2. Undaria pinnatifida. Coefficients of linear correlation (Pearson's r) between growth rates and $\Delta$ for the 2008 experiment using different starting times $\left(t_{1}\right)$ and a fixed ending time $\left(t_{2}\right.$, Day 68$)$ for growth rate calculation. For $\mathrm{AGR}_{\mathrm{L}}$ and $\mathrm{AGR}_{\mathrm{W}}$, the coefficients correspond to a power function, and, for RGR, they refer to a linear function (cf. Fig. 5). Asterisk indicates significant values $(\mathrm{p}<0.05)$

\begin{tabular}{|cccc|}
\hline$t_{1}$ & $\mathrm{AGR}_{\mathrm{L}}$ & $\mathrm{AGR}_{\mathrm{W}}$ & $\mathrm{RGR}$ \\
\hline 16 & $-0.90^{*}$ & $-0.89^{*}$ & $-0.87^{*}$ \\
28 & $-0.90^{*}$ & $-0.89^{*}$ & -0.36 \\
36 & $-0.87^{*}$ & $-0.89^{*}$ & 0.18 \\
47 & $-0.88^{*}$ & $-0.90^{*}$ & -0.05 \\
57 & $-0.78^{*}$ & $-0.90^{*}$ & 0.17 \\
\hline
\end{tabular}

are only minimally shadowed by the culture structure. This difference may have led to different irradiance regimes at the 2 stations, with lower irradiance reaching the thalli under the raft at Stn IN and, consequently, lower growth there. However, anecdotal evidence exists for differences in growth performance between the inner and outer bay, and other environmental factors that were not evaluated could be responsible for the observed results here, e.g. nutrients.

Values of $\delta^{13} \mathrm{C}$ from the thalli cultured in 2007 were higher than those from the thalli cultured in 2008 (Table 1). One reason for this was that in 2007 only the midrib was used for $\delta^{13} \mathrm{C}$ measurements, while in 2008 the entire thallus was used. In Undaria pinnatifida, the midrib shows a higher $\delta^{13} \mathrm{C}$ than the blade (authors' unpubl. data); thus, measurements including the blades will tend to show lower $\delta^{13} \mathrm{C}$. Similar trends have been observed for other kelp species (Stephenson et al. 1984, Fenton \& Ritz 1989, Fredriksen 2003).

The remaining differences in algal $\delta^{13} \mathrm{C}$ among the thalli were probably a consequence of the difference in thallus growth performance. DIC $\delta^{13} \mathrm{C}$ did not vary much, being nearly $0 \%$; thus, in the following, we only discuss $\Delta$, since these values were almost always the opposite (i.e. negative) of the thalli $\delta^{13} \mathrm{C}$ values (Eq. 1). More intense carbon assimilation should lead to lower $\Delta$, but the mechanism behind this pattern depends on how the plant assimilates carbon, by $\mathrm{CO}_{2}$ passive assimilation (Laws et al. 1995), by active $\mathrm{HCO}_{3}{ }^{-}$uptake (Sharkey \& Berry 1985), or by both processes together (Burkhardt et al. 1999, Keller \& Morel 1999). Regardless of the underlying mechanism, our results (Fig. 5) suggest that the carbon assimilation rate determined the $\Delta$ of Undaria pinnatifida in the present study.

An alternative possibility for the variation in $\Delta$ is a difference in boundary layer thickness among individuals: thicker boundary layers would lead to lower $\Delta$ (Raven et al. 1982). However, this hypothesis is difficult to verify because the boundary layer thickness depends on environmental factors, such as flow velocity, which are difficult to measure. In the present case, it is possible that water velocity was higher at Stn OUT than at Stn IN, since Stn OUT was positioned more toward the center of the bay, and water usually flows faster in this part of the bay in the bays of the region (Otobe et al. 1996). If this factor were, in fact, important in determining $\Delta$ here, $\Delta$ should have been higher at Stn OUT, in direct contrast to our observations (Fig. 5). Lower temperatures slow diffusion and may cause thicker boundary layers (Hurd 2000), and, as temperature decreased during the experiments (Fig. 2a,b), it may have affected $\Delta$. However, results show that this is probably not the case: both the range of $\Delta$ values and their distribution among the treatments were similar between the 2 collection times (Fig 5, left side). Finally, analysis of the results for the thalli maintained in meshing could be useful in further illustrating this point. The mesh should have increased boundary layer thickness, which would have led to lower $\Delta$ values (Raven et al. 1982), but some covered thalli showed much higher $\Delta$ values than uncovered thalli (Fig. 5a). This may indicate that the effect of mesh on $\Delta$ was not as important as the effect due to growth rate. In summary, our results suggest that the influence of boundary layer thickness was secondary in determining the $\Delta$ of Undaria pinnatifida in the present study.

\section{RGR versus $\Delta$}

RGR is a less biased growth rate than $\mathrm{AGR}_{\mathrm{W}}$ and $\mathrm{AGR}_{\mathrm{L}}$. RGR corresponds to the average rate of cell division in the organism and can be defined as: $\mathrm{d} W /(W \mathrm{~d} t)$, that is, the derivative of weight in time per unit of weight (Evans 1972, Hunt 1982). $\mathrm{AGR}_{\mathrm{W}}$ is defined by $\mathrm{d} W / \mathrm{d} t$, the derivative of weight in time. Therefore, $\mathrm{AGR}_{\mathrm{W}}$ is RGR times the biomass of the thallus at a given time. This means that RGR does not depend on the biomass, but $\mathrm{AGR}_{\mathrm{W}}$ does, which constitutes a bias: larger individuals with the same cellular activity (or RGR) can show different $\mathrm{AGR}_{\mathrm{W}}$. $\mathrm{AGR}_{\mathrm{L}}$ is even more biased because of the unavoidable variation in the relationship between TW and TL (Fig. 4). Because of these limitations, RGR has long been suggested to be the best measure of growth (Hunt 1982). However, the results of the present study showed that RGR in Undaria pinnatifida is not constant and that this generates several problems. For example, in 2007, $\mathrm{AGR}_{\mathrm{W}}$ and $\mathrm{AGR}_{\mathrm{L}}$ as well as direct measurements of $\mathrm{TL}$ and TW, showed that growth rate was higher at Stn OUT than at Stn IN, but RGR did not (Fig. 3, left side). In 2008, RGR showed this difference, but at the end of the culture period the difference disappeared (Fig. 3j). Thus, if RGR had been determined at the end of the 
experiment in 2008, it would not have shown a difference in growth performance between Stns IN and OUT, as was the case for the 2007 experiment. The reason for this problem is that RGR is not constant throughout the life history of an alga and commonly decreases with size, due to the fact that, as the alga grows, proportionally fewer portions of the thallus are engaged in cell division (Niklas 1994). Thus, even if the cell division rate remains constant, if the relative number of cells dividing decreases, RGR will decrease. This probably occurred in our experiment (compare Fig. $3 \mathrm{~h}$ and j), because, as Undaria pinnatifida grows, its thallus thickens, especially the central midrib. The cells in the inner part of the midrib of Laminariales do not photosynthesize, and some even lose the ability to divide after they are formed (Lee 2008).

Organic carbon in Undaria pinnatifida tissue consists of 'old' carbon, which has previously been fixed and transported to the meristem and is subsequently displaced to the tip and to the holdfast, as is common in Laminariales (Fritsch 1959, Lee 2008), and of 'new' carbon that is assimilated in the blade and transported to the meristem for growth (Wu \& Meng 1997). This mixture of old and new carbon means that $\Delta$ obtained from a given part of the thallus, or from the entire thallus, will be related to both old and new activities of the plant, provided $\Delta$ results from carbon assimilation intensity. Thus, $\Delta$ calculated from entire thallus $\delta^{13} \mathrm{C}$ would be an index of time-averaged carbon assimilation intensity, and that is why it related so well with RGR in 2008 (Fig. 5f), because it was an index of thallus growth (from Day 0 to 68), summarizing the growth activity over time. In contrast, the relatively 'instantaneous' measures of RGR in the 2007 experiment could not capture the overall RGR (or time-averaged carbon assimilation intensity), because RGR varies in time (Fig. 3j). This could explain the lack of correlation for the data in 2007 (Fig. 5e). By decreasing the time span for calculated RGR in 2008 and calculating the correlation coefficient with $\Delta$, as done in Table 2, one finds support for the explanation: the correlation soon disappears as the time span used to calculate RGR decreases, indicating the time-integrated nature of the growth index provided by $\Delta$.

Kinetic isotopic discrimination is expected, in theory, to obey a demand-supply control (Zeebe \& WolfGladrow 2001), and evidence for such a control in carbon assimilation by aquatic plants has been presented (Degens et al. 1968, Hemminga \& Mateo 1996, Staal et al. 2007). Here, the strong influence of RGR on $\Delta$ (Fig. 5f) and the almost constant concentration of dissolved inorganic carbon (Fig. 2c) are consistent with this hypothesis: if supply (dissolved inorganic carbon concentration) is nearly constant, $\Delta$ becomes almost exclusively dependent on demand (RGR), which would explain the linear relationship shown in Fig. 5f. However, the phenomenon might have been more complex than it seems. In fact, even with a constant DIC concentration in water, the changes in thallus shape can modify the carbon supply: as the thallus grows, the volume:surface area ratio increases (Niklas 1994); thus, it is possible that, even with a constant carbon concentration in the water, the relative supply for each cell may not be constant, but decrease with growth. This would cause thalli that grow more quickly to have a proportionally lower carbon supply than those that grow more slowly, and consequently a lower $\Delta$, which might be responsible for part of the difference observed in $\Delta$ among the thalli (Fig. 5f). However, an increase in the volume of the thallus in Laminariales is accompanied by some cells ceasing to divide (Lee 2008), which would be reflected as a lack of increase in carbon demand. Thus, a realistic description of the phenomenon would need to consider this factor as well. Nevertheless, the results shown in Fig. $5 \mathrm{f}$ can be explained by a simple condition of constant carbon supply and strong demand control on $\Delta$.

It is important to keep in mind that although very strong, the correlation illustrated in Fig. $5 \mathrm{f}$ may not be ubiquitous; consequently, the adoption of $\Delta$ to estimate RGR, even under environmental conditions similar to those found here, could be misleading. Further investigations are necessary to confirm the usefulness of $\Delta$ as a growth index for Undaria pinnatifida.

\section{AGR versus $\Delta$}

Besides correlating very well with RGR, $\Delta$ also correlated with $\mathrm{AGR}_{\mathrm{W}}$ and $\mathrm{AGR}_{\mathrm{L}}$, but less strongly (Fig. 5a to d). These correlations existed in both 2007 and 2008 experiments, in contrast to RGR, for which the correlation could only be observed in 2008 (Fig. 5e, f). The time trends of $\mathrm{AGR}_{\mathrm{L}}$ and $\mathrm{AGR}_{\mathrm{W}}$ were different from that of RGR: the former parameters increased for the most part as time passed, while the latter decreased substantially (Fig. 3d, h). Despite these differences, the fact is that both $\mathrm{AGR}_{\mathrm{W}}$ and $\mathrm{AGR}_{\mathrm{L}}$ depend on RGR, but, as explained before, they are also affected by the size of the thallus at the moment of measurement. This size dependence can be understood as follows: the thalli that started growing fast (with higher RGR) reach a higher biomass faster, which accumulates to increase its $\mathrm{AGR}_{\mathrm{W}}$ over the slow grower. Hence, even if the RGR of the initially slow growers eventually surpasses that of the fast growers, the difference between their $\mathrm{AGR}_{\mathrm{W}}$ may be small, because the biomass of the initially fast growers overwhelms the late fast growth of the initially slow growers. This was exactly the case observed in 2008 (Fig. 3, right side). 
One consequence of the size-dependent effect on $A G R_{W}$ and $A G R_{L}$ is that they are robust growth measurements: in contrast to RGR, it is not necessary to measure $A G R_{W}$ and $A G R_{L}$ from the beginning of the culture in order to determine which thalli grow faster. Those thalli that started growing fast continue doing so, in part because there are more 'working hands' (biomass); thus, differences among individuals measured by $A G R_{W}$ and $A_{G} R_{L}$ remain almost unchanged through the culture. This explains why the correlation between $\Delta$ and RGR deteriorated as the growth measurement interval became shorter, but that between $\Delta$ and $\mathrm{AGR}_{\mathrm{W}}$ or $\mathrm{AGR}_{\mathrm{L}}$ did not (Table 2).

In contrast to the correlation between $\Delta$ and RGR in 2008 (Fig. 5f), the regression fits for $\mathrm{AGR}_{\mathrm{W}}$ or $\mathrm{AGR}_{\mathrm{L}}$ were not linear (Fig. 5a to d). Since the 'true' relationship should be that between $\Delta$ and RGR, the deviations from linearity in the other regression fits are probably due to non-linear relationships between RGR and the other growth rates. Such non-linear relationships can be expected, because RGR is based on a logarithmic calculation (Eq. 4), while AGR is not (Eqs. 2 \& 3), and it can be mathematically demonstrated that a variable that correlates linearly with RGR will correlate approximately through a power function with $\mathrm{AGR}_{\mathrm{w}}$ (results not shown). In addition, $A_{G} R_{W}$ relates non-linearly with $\mathrm{AGR}_{\mathrm{L}}$, as can be anticipated from Fig. 4.

\section{Possibility of $\mathrm{HCO}_{3}{ }^{-}$uptake}

The correlation between $\Delta$ and RGR does not only suggest that carbon assimilation intensity was the main factor affecting $\Delta$, it also provides clues on the type of carbon assimilation mechanism functioning in this species. Here, $\Delta$ was defined in relation to DIC $\delta^{13} \mathrm{C}$, the value of which is very similar to $\mathrm{HCO}_{3}{ }^{-} \delta^{13} \mathrm{C}$ (Fig. 2e, f). $\mathrm{CO}_{2}$ and $\mathrm{HCO}_{3}{ }^{-}$are the forms of inorganic carbon that can be absorbed by aquatic plants (Raven 1997); the data in Fig. $5 \mathrm{f}$ can be used to evaluate which form was being absorbed. This can be done by examining the intercept of the regression line between RGR and $\Delta$ on the vertical axis, the value of which was $28.6 \%$, a $\Delta$ value that could nearly be attributed to RUBISCO activity alone (Raven 1997). The intercept of this regression can, thus, be understood as the $\Delta$ value independent of the influence of carbon assimilation (Laws et al. 1995). This is consistent with $\mathrm{HCO}_{3}{ }^{-}$ uptake: if $\mathrm{CO}_{2}$ were being assimilated, the intercept would be nearly $39 \%$, because $\mathrm{CO}_{2} \delta^{13} \mathrm{C}$ was nearly $10 \%$ lower than DIC $\delta^{13} \mathrm{C}$ considering the temperatures at which the experiment was done (Fig. 2e,f). This result partially agrees with data from previous investigations conducted with the related species Alaria esculenta, for which direct $\mathrm{HCO}_{3}{ }^{-}$or $\mathrm{CO}_{2}$ uptake was proposed after external carbonic anhydrase conversion from $\mathrm{HCO}_{3}^{-}$(Surif \& Raven 1989). Our results suggest that this enzyme does not participate in carbon uptake, because, if it did, the intercept of the regression line would also be approximately $39 \%$, since the conversion from $\mathrm{HCO}_{3}{ }^{-}$to $\mathrm{CO}_{2}$ intermediated by this enzyme would also imply a discrimination around 10\% (Paneth \& O'Leary 1985). In conclusion, it seems that direct active $\mathrm{HCO}_{3}^{-}$uptake is probably the main form of carbon assimilation utilized by Undaria pinnatifida in nature.

The same type of investigation (i.e. the study of $\Delta$ related to RGR in order to determine aspects of carbon uptake) in different species could be fruitful in explaining aspects of their ecology, such as their distribution throughout the littoral zone (Surif \& Raven 1989). However, studies like the one conducted here are time consuming and labor intensive. A more efficient approach to evaluate the relationship between carbon assimilation intensity and $\Delta$ is to employ short-term laboratory incubations (Carvalho et al. 2009).

Acknowledgements. We express our gratitude to M. Konishi, who kindly allowed the use of his culture structures and Undaria pinnarifida seeds, and to K. Niinuma for allowing the research to be done in his fisheries administrative section. We also acknowledge the tremendous help of Mr. G. Doomori and Mr S. Doita during part of the field sampling. Finally, the constructive comments of an anonymous reviewer are acknowledged.

\section{LITERATURE CITED}

Brinkhuis BH (1985) Growth patterns and rates. In: Littler MM, Littler DS (eds) Handbook of phycological methods-Ecological field methods: macroalgae. Cambridge University Press, Cambridge, p 461-477

Burkhardt S, Riebesell U, Zondervan I (1999) Effects of growth rate, $\mathrm{CO}_{2}$ concentration, and cell size on the stable isotope fractionation in marine phytoplankton. Geochim Cosmochim Acta 63:3729-3741

Carvalho MC, Hayashizaki K, Ogawa H, Kado R (2007) Preliminary evidence of growth influence on carbon stable isotope composition of Undaria pinnatifida. Mar Res Indones 32:185-188

Carvalho MC, Hayashizaki K, Ogawa H (2009) Short-term measurement of carbon stable isotope discrimination in photosynthesis and respiration by aquatic macrophytes. J Phycol 45:in press

Casas G, Scrosati R, Piriz ML (2004) The invasive kelp Undaria pinnatifida (Phaeophyceae, Laminariales) reduces native seaweed diversity in Nuevo Gulf (Patagonia, Argentina). Biol Invasions 6:411-416

> Chanton JP, Lewis FG (1999) Plankton and dissolved inorganic carbon isotopic composition in a river-dominated estuary: Apalachicola Bay, Florida. Estuaries 22:575-583

> Cooper LW, DeNiro MJ (1989) Stable carbon isotope variability in the seagrass Posidonia oceanica: evidence for light intensity effects. Mar Ecol Prog Ser 50:225-229

Degens ET, Guillard RRL, Sackett WM, Hellebust JA (1968) 
Metabolic fractionation of carbon isotopes in marine plankton, Part I. Temperature and respiratory experiments. Deep-Sea Res 15:1-9

Evans GC (1972) The quantitative analysis of plant growth, Vol 1. Blackwell Scientific Publications, Oxford

Fenton GE, Ritz DA (1989) Spatial variability of ${ }^{13} \mathrm{C}:{ }^{12} \mathrm{C}$ and D:H in Ecklonia radiata (C. Ag.) J. Agardh (Laminariales). Estuar Coast Shelf Sci 28:95-101

France RL (1995) Carbon-13 enrichment in benthic compared to planktonic algae: foodweb implications. Mar Ecol Prog Ser 124:307-312

Fredriksen S (2003) Food web studies in a Norwegian kelp forest based on stable isotope $\left(\delta^{13} \mathrm{C}\right.$ and $\left.\delta^{15} \mathrm{~N}\right)$ analysis. Mar Ecol Prog Ser 260:71-81

Fritsch FE (1959) The structure and reproduction of the algae, Vol II. Cambridge University Press, Cambridge

Grice AM, Loneragan NR, Dennison WC (1996) Light intensity and the interactions between physiology, morphology and stable isotope ratios in five species of seagrass. J Exp Mar Biol Ecol 195:91-110

Hay CH, Luckens PA (1987) The Asian kelp Undaria pinnatifida (Phaeophyta: Laminariales) found in a New Zealand harbour. NZ J Bot 25:329-332

Hemminga MA, Mateo MA (1996) Stable carbon isotopes in seagrasses: variability in ratios and use in ecological studies. Mar Ecol Prog Ser 140:285-298

Hunt R (1982) Plant growth curves - the functional approach to plant growth analysis. Edward Arnold, London

Hurd CL (2000) Water motion, marine macroalgal physiology, and production. J Phycol 36:453-472

Hurlbert SH (1984) Pseudoreplication and the design of ecological field experiments. Ecol Monogr 54:187-211

Keller K, Morel FMM (1999) A model of carbon isotopic fractionation and active carbon uptake in phytoplankton. Mar Ecol Prog Ser 182:295-298

Kroopnick PM (1985) The distribution of ${ }^{13} \mathrm{C}$ of $\Sigma \mathrm{CO}_{2}$ in the world ocean. Deep-Sea Res 32:57-84

Kübler JE, Raven JA (1994) Consequences of light limitation for carbon acquisition in three rhodophytes. Mar Ecol Prog Ser 110:203-209

Kübler JE, Raven JA (1995) The interaction between inorganic carbon acquisition and light supply in Palmaria palmata (Rhodophyta). J Phycol 31:369-375

Laws EA, Popp BN, Bidigare RR, Kennicutt MC, Macko SA (1995) Dependence of phytoplankton carbon isotopic composition on growth rate and $\left[\mathrm{CO}_{2}\right]$ aq: theoretical considerations and experimental results. Geochim Cosmochim Acta 59:1131-1138

Lee RE (2008) Phycology. Cambridge University Press, Cambridge

Maberly SC, Raven JA, Johnston AM (1992) Discrimination between ${ }^{12} \mathrm{C}$ and ${ }^{13} \mathrm{C}$ by marine plants. Oecologia 91: 481-492

Maindonald J, Braun WJ (2007) Data analysis and graphs using $\mathrm{R}$ - an example-based approach. Cambridge University Press, Cambridge

> Mook WG, Bommerson JC, Staverman WH (1974) Carbon isotope fractionation between dissolved bicarbonate and gaseous carbon dioxide. Earth Planet Sci Lett 22:169-176

Niklas KJ (1994) Plant allometry: the scaling of form and process. University of Chicago Press, Chicago, IL

O'Leary MH (1981) Carbon isotope fractionation in plants.

Editorial responsibility: Rodney Forster,

Lowestoft, UK
Phytochemistry 20:553-567

Ogawa H (2004) Wakame. In: Masao O (ed) Biology and technology of economic seaweeds. Uchida Rokakuho, Tokyo, p 42-58

Otobe H, Takeuchi I, Konashi S (1996) Water flow structure near the Nanamodori point in Otsuchi Bay. Otsuchi Marine Research Center Report 21:51-58

Paneth P, O'Leary MH (1985) Carbon isotope effect on dehydration of bicarbonate ion catalyzed by carbonic anhydrase. Biochemistry 24:5143-5147

> Peterson BJ, Fry B (1987) Stable isotopes in ecosystem studies. Annu Rev Ecol Syst 18:293-320

Raven JA (1997) Inorganic carbon acquisition by marine autotrophs. Adv Bot Res 27:85-209

Raven JA, Beardall J, Griffiths H (1982) Inorganic C-sources for Lemanea, Cladophora, and Ranunculus in a fastflowing stream: measurements of gas exchange and of carbon isotope ratio and their ecological implications. Oecologia 53:68-78

> Raven JA, Johnston AM, Kübler JE, Korb R and others (2002) Mechanistic interpretation of carbon isotope discrimination by marine macroalgae and seagrasses. Funct Plant Biol 29:355-378

Sharkey TD, Berry JA (1985) Carbon isotope fractionation of algae as influenced by an inducible $\mathrm{CO}_{2}$ concentrating mechanism. In: Lucas WJ, Berry JA (eds) Inorganic carbon uptake by aquatic photosynthetic organisms. The American Society of Plant Physiologists, Rockville MD, p 389-401

Staal M, Thar R, Kuhl M, van Loosdrecht MCM, Wolf G, Brouwer JFC, Rijstenbil JW (2007) Carbon isotope fractionation in developing natural phototrophic biofilms. Biogeosciences 4:613-626

Stephenson RL, Tan FC, Mann KH (1984) Stable carbon isotope variability in marine macrophytes and its implications for food web studies. Mar Biol 81:223-230

Stumm W, Morgan JJ (1981) Aquatic chemistry, an introduction emphasizing chemical equilibria in natural waters. John Wiley and Sons, New York

Surif BM, Raven JA (1989) Exogenous inorganic carbon sources for photosynthesis in seawater by members of the Fucales and the Laminariales (Phaeophyta): ecological and taxonomic implications. Oecologia 78:97-105

Surif BM, Raven JA (1990) Photosynthetic gas exchange under emersed conditions in eulittoral and normally submersed members of the Fucales and the Laminariales: interpretation in relation to $\mathrm{C}$ isotope ratio and $\mathrm{N}$ and water use efficiency. Oecologia 82:68-80

Wefer G, Killingley JS (1986) Carbon isotopes in organic matter from a benthic alga Halimeda incrassata (Bermuda): effects of light intensity. Chem Geol 59:321-326

> Wiencke C, Fischer G (1990) Growth and stable carbon isotope composition of cold-water macroalgae in relation to light and temperature. Mar Ecol Prog Ser 65:283-292

> Wu C, Meng J (1997) Translocation of assimilates in Undaria and its cultivation in China. Hydrobiologia 352:9-16

Yoshikawa T, Takeuchi I, Furuya K (2001) Active erosion of Undaria pinnatifida Suringar (Laminariales, Pheophyceae) mass-cultured in Otsuchi Bay in northeastern Japan. J Exp Mar Biol Ecol 266:51-65

Zeebe RE, Wolf-Gladrow D (2001) $\mathrm{CO}_{2}$ in seawater: equilibrium, kinetics, isotopes. Elsevier, Amsterdam

Submitted: January 24, 2008; Accepted: January 26, 2009

Proofs received from author(s): April 1, 2009 